\section{AB1020 PILOT ASSESSMENT OF CURRENT CHRONIC GOUT TREATMENT IN RUSSIA}

A.A. Popov ${ }^{1}$, O.V. Teplyakova ${ }^{2}$, T.A. Popova ${ }^{3}$, A.V. Sarapulova² ${ }^{2}$ P. A. Palabugina ${ }^{1} .{ }^{1}$ Hospital Therapy Dept, ${ }^{2}$ Outpatient Therapy Dept., URALS STATE MEDICAL UNIVERSITY; ${ }^{3}$ Rheumatology Dept., City Clinical Hospital 40 , Ekaterinburg, Russian Federation

Background: In 2016 EULAR evidence based clinical guidelines on Gout treatment have been updated. ${ }^{1}$

Objectives: to assess current daily practice physicians' approach to management of chronic gout patients

Methods: a cross-sectional anonymous survey had been offered to hospital and outpatient departments physicians dealing with gout patients resulting in 97 backfeed replies yielded. This publication deals with chronic gout treatment practice. Results: all survey participants were divided into 3 groups. Group 1 consisted of 18 rheumatologists (professional experience median 19.6 years, range 1 to 43 ), group 2 included 60 general practitioners (GP, professional experience 27; 4-47), group 3 included other specialists (cardiologists, surgeons etc.) who reported frequent contacts with gout patients (professional experience 16.5; 1-44). Rheumatologists reported to contact median 15 (range 2-40) gouty subjects per month while group 2 reported to see $3^{1-10}$ and group 3 consults $4^{1-12}$ patients per month. All rheumatologists and 45 GPs reported initiation of allopurinol or febuxostat after gouty arthritis resolution, while 11 general practitioners did not start antihyperuricemic drugs in subjects with kidney and/or cardiovascular comorbidities. In Group 3 only 6 responders had experience of antihyperuricemic drugs administration, but 3 of them reported allopurinol initiation during gout flare. Only 2 rheu matologists and 2 GPs were aware of gout flare low dose colchicin prophylaxis during allopurinol dose adjustment. Administration of maximal allopurinol daily maintenance doses over $300 \mathrm{mg}$ was reported only by 7 rheumatologists and 7 GPs. Other specialists did not have any personal experience of allopurinol dose adjustment. By responders' assessment every 2-3 patient continues to experience gout flares in spite of prescribed treatmen

Conclusions: intensive educational intervention is urgently required to change current practice of chronic gout treatment in Russia.

\section{REFERENCE:}

[1] Richette P, et al. 2016 updated EULAR evidence-based recommendations for the management of gout. Ann Rheum Dis 2017;76:29-42

Disclosure of Interest: None declared

DOI: 10.1136/annrheumdis-2018-eular.3345

\section{AB1021 ANEURYSMAL BONE CYSTS OF THE SPINE: 4 CASE REPORTS AND REVIEW OF LITERATURE}

A. Romdhane, N. Karmani, J. Kallel, I. Ben Said. Neurosurgery, National Institute of Neurology, Tunis, Tunisia

Background: Aneurysmal bone cysts $(A B C)$ are rare, benign, highly vascular pseudotumors of unknown cause. It most often affects individuals during their second decade of life.

Objectives: Our goal was to document the clinical characteristics, diagnostic modalities and treatment results of ABCs.

Methods: We reviewed our institution's database over a period of 15 years to identify patients diagnosed with aneurysmal bone cysts of the spine. Four patients underwent surgery in our department (2 men and 2 women). For those four patients, we tabulated the clinical characteristics, location, diagnostic modalities and treatment.

Results: The clinical manifestations were gait disturbance in 2 patients and legpain in the other two. The tumour occurred in the dorsal spine in 2 cases and in the lumbar spine in the other two. All patients underwent surgical resection with total removal in only 2 patients. Postoperatively, clinical signs improved in all patients. Only one case presented tumour recurrence requiring second intervention and instrumentation.

ABCs constitute approximately $1.5 \%$ of spinal bone tumours. They usually affect the posterior elements of the spine. MRI is the most useful modality for preoperative planning. It also helps to evaluate the fluidfluid level, which is characteristic for $A B C$ on MRI. The differential diagnosis is mainly with giant cell tumours and osteoblastomas. The primary option for treatment is surgery. Instrumentation is sometimes necessary because of the increased risk of postoperative instability, especially in cervical spine surgery. The recurrence rate is $20 \%$ to $30 \%$ in case of incomplete resection.

Conclusions: $\mathrm{ABC}$ are benign lesions. Surgical resection en bloc has the lowest recurrence rate. Instrumentation is sometimes necessary because of the increased risk of postoperative instability.

\section{REFERENCES}

[1] Boriani S, De lure F, Campanacci L, et al. (2001) Aneurysmal bone cyst of the mobile spine: report on 41 cases. Spine. 26:27-35

[2] Pennekamp W, Peters S, Schinkel C, Kuhnen C, Nicolas V, Muhr G, Frangen TM (2008) Aneurysmal bone cyst of the cervical spine. Eur Radio 18:2356-2360

[3] Sundaram M, McDonald DJ, Steigman CK, Bocchini T (1997) Metachro nous multiple aneurysmal bone cysts. Skeletal Radiol 26(9):564-567

[4] Keenan S, Bui-Mansfield LT (2006) Musculoskeletal lesions with fluid-fluid level: a pictorial essay. J Comput Assist Tomogr 30:517-524

[5] Saccomanni R (2008) Aneurysmal bone cyst of spine: a review of litera ture. Arch Orthop Trauma Surg 128:1145-1147

Disclosure of Interest: None declared

DOI: 10.1136/annrheumdis-2018-eular.3105

\section{AB1022 EFFICACY AND TOLERANCE OF SODIUM THIOSULFATE INJECTION IN CALCIFIC TENDINOPATHY OF THE ROTATOR CUFF}

$\underline{\text { C. Darrieurtort-Laffite }}^{1}$, T. Garraud ${ }^{1}$, A. Bertrand-Vasseur ${ }^{2}$, B. Le Goff ${ }^{1}$

${ }^{1}$ RHEUMATOLOGY UNIT; ${ }^{2}$ RADIOLOGY UNIT, HOPITAL HOTEL DIEU/HME, NANTES CEDEX 1, France

Background: Calcific tendinitis of the rotator cuff is one of the most common causes of shoulder pain. Ultrasound guided percutaneous lavage of calcific tendinopathy (UGPL) is indicated when conservative treatments have failed. It has been shown that dense calcifications are associated with a higher risk of treatment failure. Sodium thiosulfate (STS) has recently been used with success in the treatment of tumoral calcinosis. We hypothesised that STS lavage could be of interest in the treatment of dense calcification of the rotator cuff.

Objectives: To evaluate the tolerance and efficacy of sodium thiosulfate lavage in the treatment of calcific tendinitis

Methods: This was a prospective phase II open label study. We included only patients with a type A calcification according to the Molé classification. Patients were treated with a US-guided single needle technic. When backflow of calcific material could be identified in the syringe, lavage of the deposit was performed using STS 25\% until the backflow becomes clear followed by the injection of $1 \mathrm{~mL}$ $(250 \mathrm{mg})$ of STS inside the calcific deposit. Finally, $1.5 \mathrm{~mL}$ of cortivazol was injected in the subacromial bursa. All patients had follow-up visits at 1 week, 1 month and 3 months after intervention. At each time point, VAS pain at rest and during activities was recorded and US and X-ray were performed. Our primary outcome was the percentage of patients with more than $50 \%$ of decrease of the calcification size at 1 month. Based on our experience and on the literature, we expected than more than $60 \%$ of the patients should have more than $50 \%$ of decrease in their calcification for the results to be significant.

Results: A total of 17 patients were included. Mean age was $50 \pm 11$ years. There were 9 female (52.9\%). Baseline VAS at rest and during daily activities was a mean $40.2 \pm 25.9$ and $65.5 \pm 21.6(27-91)$ respectively. Calcification involved the supraspinatus in 12 cases $(70.6 \%)$ and the infraspinatus in 5 cases $(29.4 \%)$. Mean surface on radiography was $80.7 \mathrm{~mm} 2 \pm 52.4$ and the calcification longest size was $18.8 \pm 7.1 \mathrm{~mm}$. All patients underwent the entire procedure with no adverse event apart of a mild and transient vasovagal reaction. Calcium backflow could be obtained in 15 patients $(88.2 \%)$ with a small amount of calcium in 8 cases $(53.3 \%)$ and a large quantity in 7 cases $(46.7 \%)$. We found that 5 patients $(30 \%)$ had more than $50 \%$ decrease of their calcific deposit at 1 month and $8(47 \%)$ patients at 3 months. VAS pain during activities and at rest decreased significantly from $65 \pm 22$ and $40.2 \pm 26$ at baseline to $37.8 \pm 31$ and $24.1 \pm 24$ at 3 month respectively $(p=0.0004 ; p=0.001)$

Conclusions: Overall, our study is the first to evaluate the tolerance and efficacy of sodium thiosulfate for the treatment of the calcifications of the rotator cuff. We could not demonstrate a significant effect of one STS lavage and injection in patients with dense calcification. This treatment was well tolerated with no side effect occurring during the procedure and the follow-up. New studies using larger volume and repeated injections of STS will be needed to definitely conclude on the interest of this molecule in the treatment of calcific tendinopathies.

Disclosure of Interest: None declared DOI: 10.1136/annrheumdis-2018-eular.5687 